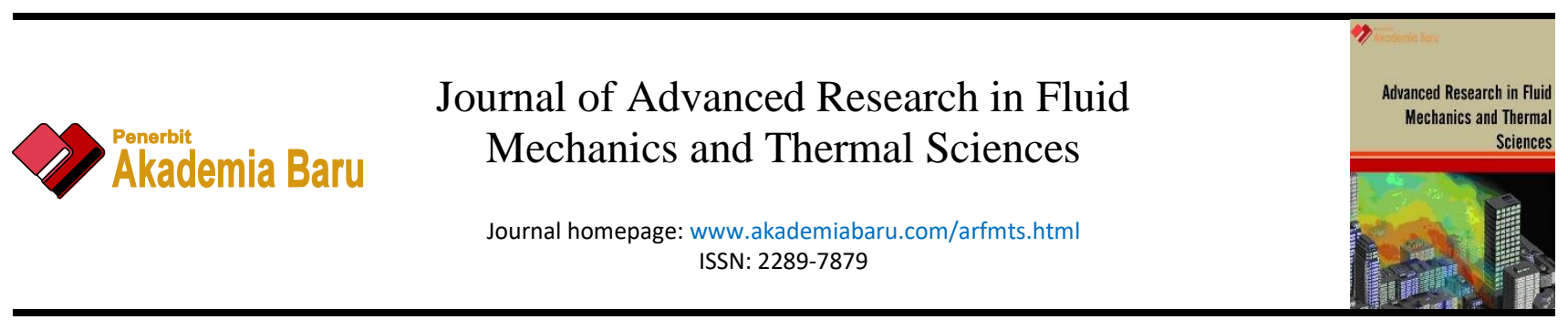

\title{
Subsurface Vortex Control Parametric Study at Submersible Pump Intake Using Plate-Type Floor Splitters
}

\author{
Zambri Harun ${ }^{1, *}$, Tajul Ariffin Norizan ${ }^{1}$, Shahrir Abdullah¹, Mazharul Islam² \\ Department of Mechanical and Manufacturing Engineering, Faculty of Engineering and Built Environment, UKM Bangi, 43600, Malaysia \\ Department of Mechanical and Production Engineering, Ahsanullah University of Science and Technology, 141 \& 142, Love Road, Tejgaon \\ Industrial Area, Dhaka-1208, Bangladesh
}

\section{ARTICLE INFO}

\section{Article history:}

Received 20 April 2020

Received in revised form 28 July 2020

Accepted 5 August 2020

Available online 20 September 2020

\section{ABSTRACT}

Vortex formation near the pump inlet in the sump during intake is a phenomenon that needs to be controlled to maximize the pump efficiency. In this study, five variants of an AVD type called the plate type floor splitter are installed in a single intake pump sump model to evaluate the effect of geometry of the floor splitter on the effectiveness of vortex control in the intake flow. The acceptance criteria according to ANSI HI 9.8 2012 standard are that the vortex formed in the sump must be eliminated and the swirl angle in the flow must not exceed $5^{\circ}$. The submergence of the inlet was varied to observe the swirl reduction effect at different water levels. All floor splitter variants employed in this study have successfully eliminated the vortex but most of them did not manage to reduce the swirl angle below $5^{\circ}$ as required. The variants with different heights displayed significant differences in swirl angle values with higher variants produce greater swirl angle reduction. The highest floor splitter variant managed to produce a swirl angle reduction below $5^{\circ}$. With varying lengths, however, the swirl angle values did not differ much in each case with the installation of the floor splitter variants. The advantage of the long floor splitter is that the fluctuation of swirl angle values is minimum for all submergence depths greater than 0.9 times the minimum inlet submergence which implies that the swirl reduction effect is less affected by the change in water level. By combining the advantages of both floor splitter design variation, the optimal design of plate type floor splitter can be achieved.

Keywords:

Anti-vortex device; floor splitter

\section{Introduction}

The study of vortex formation in pump sump during intake for pumps with wet pit installation has been an ongoing effort by many researchers for the past decades. Although vortices may occur in dry pit installation as well, the effects are more detrimental for the wet pit installation due to the fact that the pump inlet is submerged in water and therefore the vortices can directly come in contact with the pump impeller and cause damages which will affect the pump performance [1]. This work

\footnotetext{
* Corresponding author.

E-mail address: zambri@ukm.edu.my
}

https://doi.org/10.37934/arfmts.75.3.7380 
will complement vortex-reduction effort in intake pipe which eventually affect impeller and pump performance [2]. There are guidelines proposed by organizations related to pump intake design such as ANSI [3], BSI [4] and JSME [5] which could help eliminate or at least control the formation of vortices in pump sump. These guidelines mainly focus on the geometry of the pump sump in the vicinity of the inlet where sharp edges or curvatures in the sump may alter the uniformity of the intake flow and thus create high vorticity regions which will be the source of vortex formation [6]. When space is not a limitation, multi-bay pump sump approach could be used e.g. [7-8]. However, optimal design of pump sump may not be achieved in certain cases, for example limited space for the construction of pump sump [8], low channel depth [9], which cause operational restrictions that prevent adequate submergence of the pump and pump stations undergoing retrofitting works and modification of the existing pump sump structure. The limitations mentioned above are more common in urban areas because of the costs of relocating existing infrastructure. Studies have been conducted to address the different pump sump geometries and their effects on the vortex in the intake pipes [10-11]. Some of these solutions are may work such as installing a splitter in the pipe acting as a flow straightener [12] or installing a flowing device to suppress surface-vortices [13]. In a country like Malaysia which experiences both dry and wet seasons [14], knowledge in flow stability in pump sump is meaningful in both scenarios, the correct approach for low water levels in farming areas during dry season and the approach to counter highwater levels and turbulent flows during wet season.

Alternative remedial measures for these cases can be carried out by installing a control feature known as anti-vortex device (AVD). There are many types of AVD that can be used to control vortex formation, depending on the type of vortex that occurs in the sump. Generally, vortices in a pump sump can be divided into two main categories, namely free surface vortex and subsurface vortex. Free surface vortex may be eliminated by ensuring the submergence of the pump inlet as deep as possible. The detection of free surface vortex is also straight forward as it can be observed at the water surface. On the other hand, subsurface vortex is a more complex as it occurs under the surface level and could not be eliminated even with adequate submergence of the pump inlet. The occurrence of subsurface vortices is mainly due to small clearance under the suction inlet, high pump suction strength which results in high Froude Number and unsuitable sump geometry which causes non uniform approach flow to the inlet. This problem may be corrected by using a floor splitter. According to the study by Kang et al., [15], the cross-sectional feature of the floor splitter may influence the vortex elimination effect of the splitter. Kim et al., [16] also proposed that the height of floor splitter may change the profile of the intake flow and worsen the vorticity at the pump inlet if the height of the splitter exceeds 0.2 times the diameter of the inlet. In this study, five variants of plate type floor splitter are tested in a pump sump model to evaluate the effects of geometry on the effectiveness of vortex reduction.

\section{Methodology}

The experimental setup is shown in Figure 1. The rig consists of a single intake pump sump model with a closed loop piping system. The test section is made from acrylic to allow observation of any vortex formed at the suction inlet. The suction end is an acrylic pipe with bell shaped inlet resembling a real submersible pump. This is an extended experiment after earlier ones which showed that the biggest reduction in swirl angle was displayed by biggest gap between the floor splitter and the inlet pipe [17-19].

A device called the swirl meter has been installed in the suction pipe at a distance about 4 times the inlet diameter from the suction inlet to measure the swirl angle in the intake flow. The design of 
the measurement device complies with ANSI HI 9.8-2012 standard [3] and the measurement procedures are performed according to the standard. When the pump is in operation, the swirl in the intake flow will rotate the swirl meter blade and the number of rotations along with its respective direction, either clockwise or anti-clockwise, are recorded for the period of 10 minutes. The number of rotations of the blade for every 30 seconds within the measurement period were also recorded to determine the short period swirl angles while the total number of rotations for the 10-minute period gives the average swirl angle. From the number of rotations of the swirl meter, the swirl angle $\theta$ can be calculated by the following equation [15].

$\theta=\tan ^{-1} \frac{\pi d n}{u}$

where, $d$ is the inner diameter of the suction pipe, $u$ is the average axial velocity at the position of the swirl meter, and $n$ is the number of swirl meter rotations. The value for $u$ is set to $0.094 \mathrm{~mm}$ in this experiment and $u$ is controlled at a constant value of $1.44 \mathrm{~m} / \mathrm{s}$ by using variable speed drive (VSD) to control the pump speed.
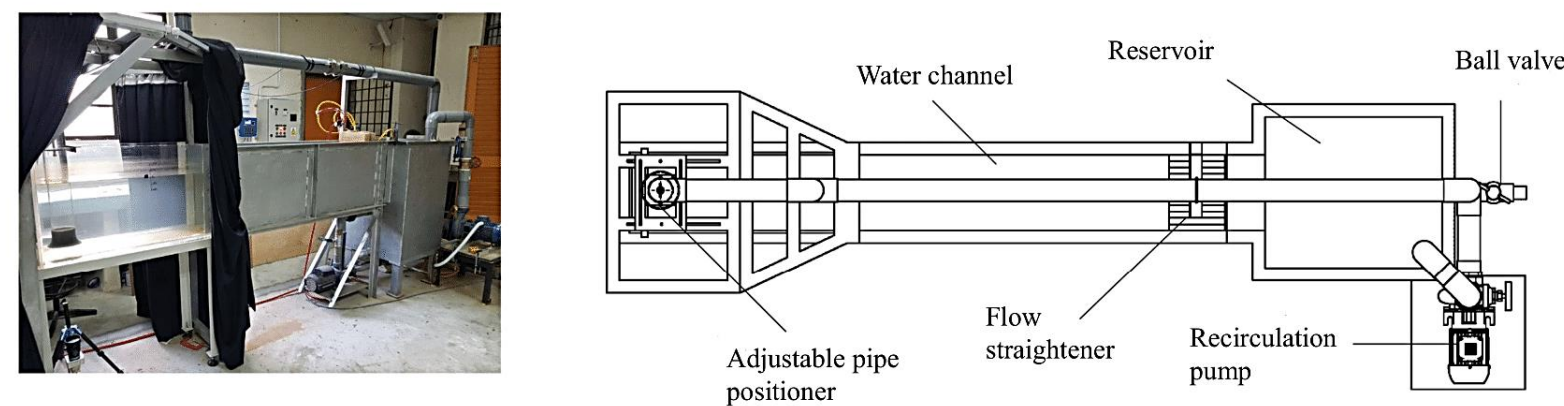

$\underline{\text { TOP VIEW }}$

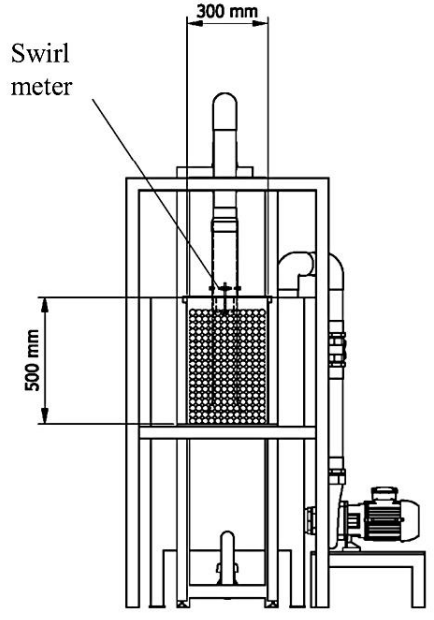

FRONT VIEW

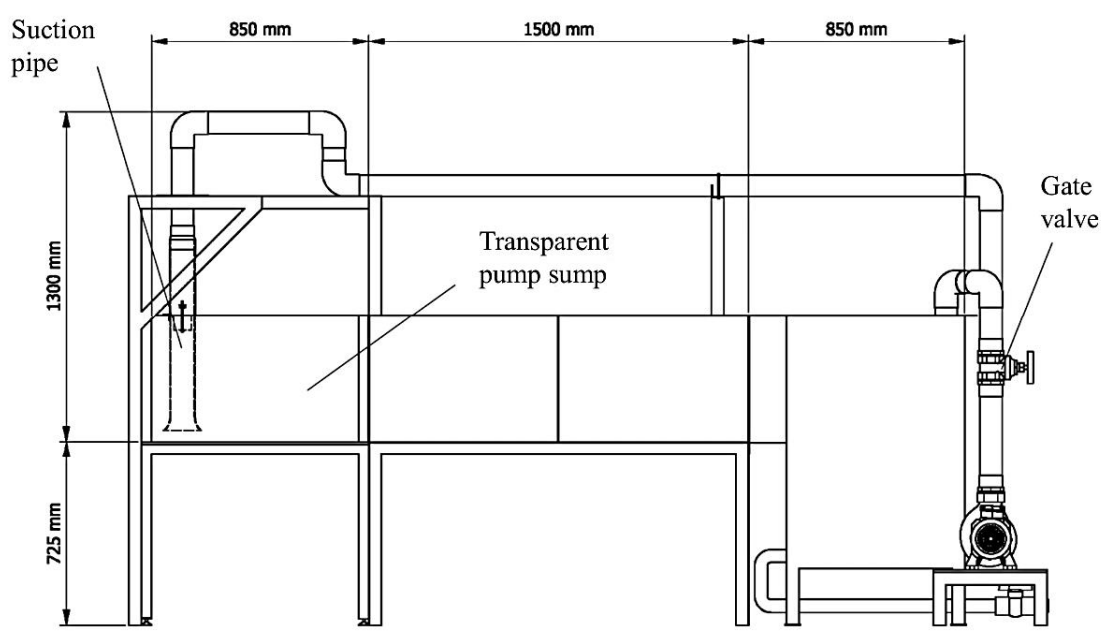

SIDE VIEW

Fig. 1. Experimental rig of the study located at the Coastal and Water Resources Engineering Laboratory, Universiti Kebangsaan Malaysia

The speed is monitored by calculating the flow rate from an ultrasonic flow meter. The rotation count is set to be the number of revolutions per second. According to ANSI HI 9.8-2012, the acceptable swirl angle value is below $5^{\circ}$ and any value above that should be reduced by installing 
AVD. As the focus of this study is the reduction of subsurface vortices, therefore floor splitter has been considered as the best AVD type for the task. Floor splitter specimens are placed directly beneath the inlet and at the center of the inlet diameter. There are five variants tested in this study in which variant AVD1 is the base shape. Variant AVD2 and AVD3 represent variant 1 but with different heights, while variant AVD4 and AVD5 are designed based on variant 1 but with different lengths. The shapes of the floor splitter variants are shown in Figure 2.

In order to obtain comprehensive results, the inlet submergence has been varied between 0.8 to 1.2 times the value of minimum inlet submergence $S_{\min }$, the submergence needed to prevent the formation of free surface vortices. $S_{\min }$ has been calculated by the following equation [3].

$S_{\min }=D\left(1.0+2.3 F r_{i n}\right)$

where, $D$ is the inlet diameter (which is $150 \mathrm{~mm}$ ), and $F r_{\text {in }}$ is the Froude Number at the inlet. Based on the above equation, the inlet Froude Number must be determined prior to the calculation of $S_{\min }$. $F r_{i n}$ can be calculated by using the following equation.

$F r_{i n}=\frac{v_{\text {in }}}{\sqrt{g D}}$

In the present study, $v_{\text {in }}$ has been chosen as $0.58 \mathrm{~m} / \mathrm{s}$ and therefore $F r_{\text {in }}$ equals to 0.48 . From Eq. (2) the value for $S_{\min }$ is $316 \mathrm{~mm}$. An inclined floor with $30^{\circ}$ inclination angle is placed at a distance about 5 times the inlet diameter from the suction inlet to create non uniform flow in the sump for the initiation of vortex at the inlet.

AVD1

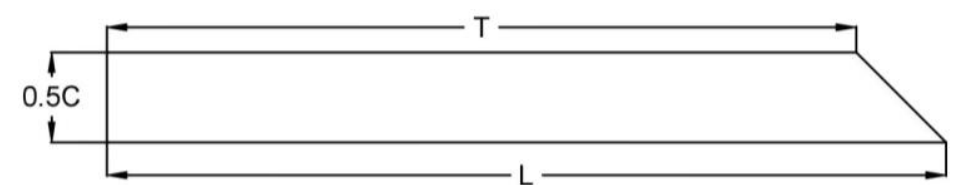

AVD2

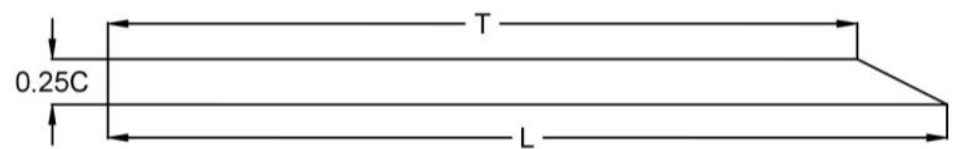

AVD3

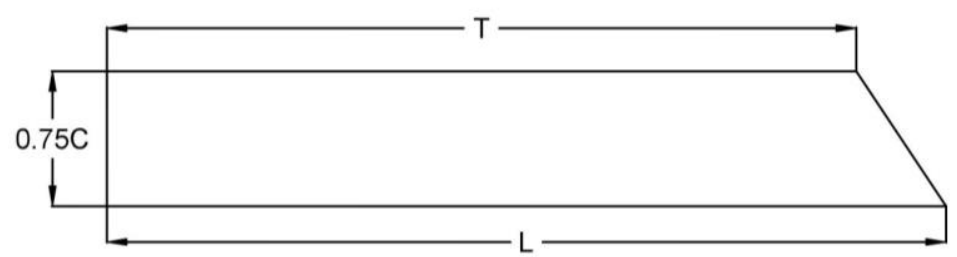

$\mathrm{D}=$ diameter of inlet $=150 \mathrm{~mm}$

$\mathrm{C}=$ clearance under the inlet $=45 \mathrm{~mm}$

$\mathrm{T}=$ distance from backwall to farther circumference of inlet $=187.5 \mathrm{~mm}$

$\mathrm{L}=$ default length of floor splitter $=$ $\mathrm{T}+0.5 \mathrm{C}=210 \mathrm{~mm}$

AVD4

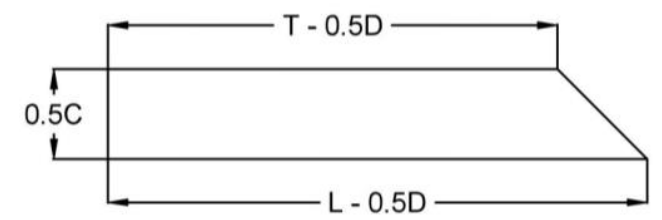

AVD5

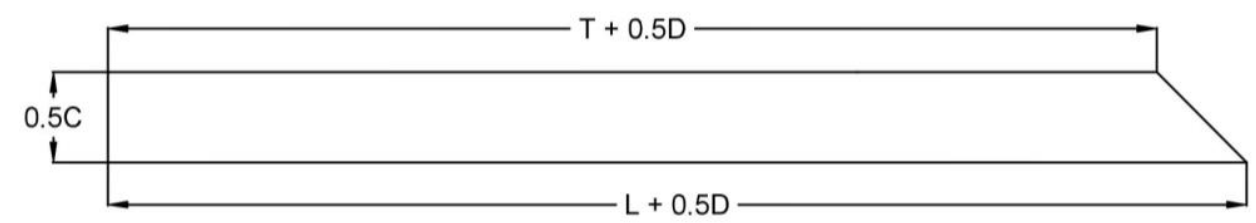

Fig. 2. Floor splitter variants tested in the experiment 


\section{Results and Discussions}

The swirl angle values for all cases with and without the installation of every floor splitter variant were recorded and evaluated. It has been observed that the subsurface vortex formed at the sump floor, as shown in Figure 3, has been successfully eliminated by the floor splitter installation. However, the swirl angle values remain high for certain floor splitter variants which propose that improvement must be carried out on the floor splitter design.

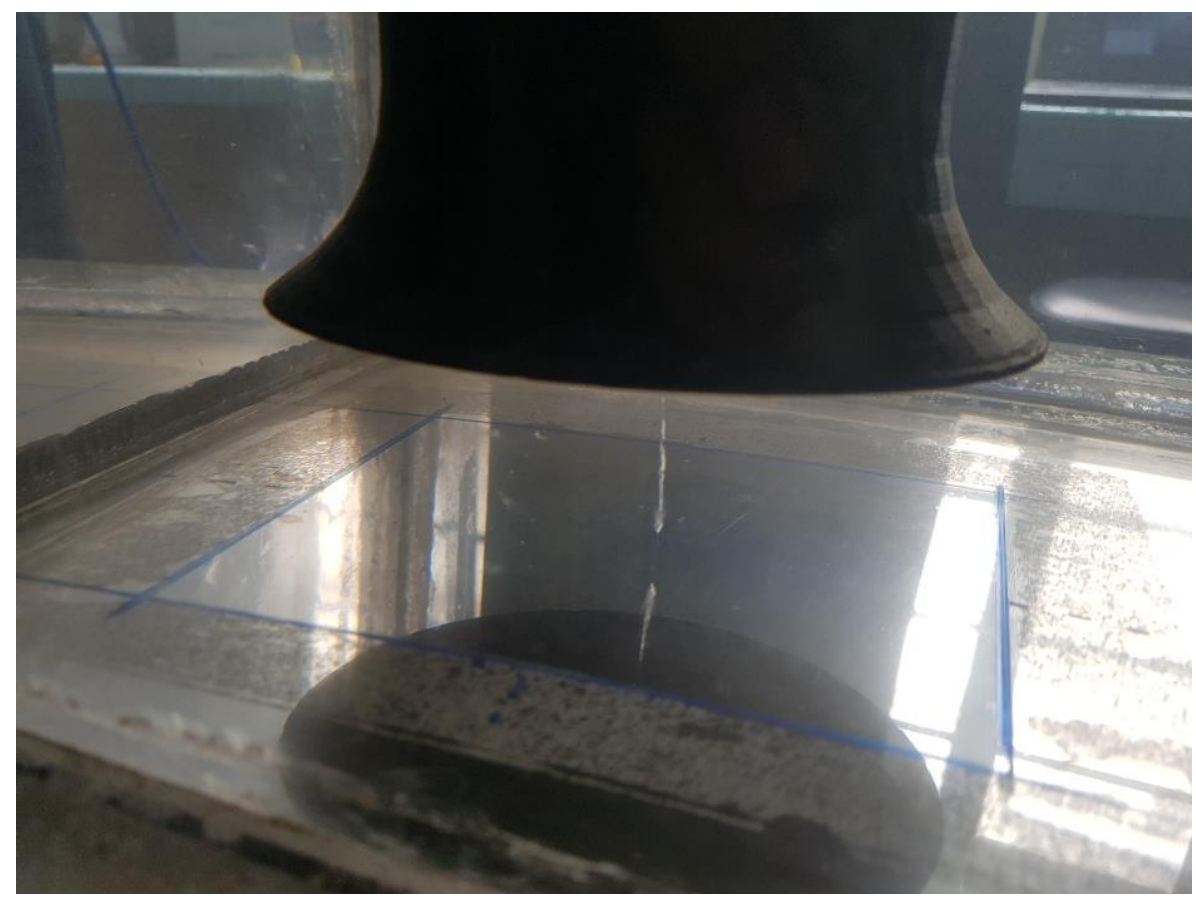

Fig. 3. Subsurface vortex formed at the sump floor

The data is presented in two categories which are differentiated according to the floor splitter variant designs. Figure 4 shows the swirl angle values for the floor splitters with varying heights while Figure 5 represents the swirl angle values for the floor splitters with varying lengths. Generally, the swirl angle values are higher at lower $S_{\min }$ values and relatively constant when the value of $S_{\min }$ between 0.9 and 1.1 before increasing again for values of $S_{\min }$ greater than 1.1. This trend indicates that the swirl angle values are stable when the submergence is within $\pm 10 \%$ from $S_{\min }$ and increase in value when the submergence lies outside the stated range due to increase in velocity gradient near the suction inlet. The stationary trend of swirl angle values is also contributed due to the inception of free surface vortex near $S_{\min }$ which hinders the rotation of swirl meter blade and ultimately reduce the increment of swirl angle. For the case with floor splitter variants of different heights, it can be observed that the increase in floor splitter height reduces the swirl angle values significantly. The swirl reduction effect increases with increasing swirl angle as shown in Figure 4. For submergence ratio greater than 1.1, the swirl angle values are decreased further with the installation of AVD1, AVD2 and AVD3. AVD3 displays the smallest margin between the highest and the lowest swirl angles which is $1.65^{\circ}$. AVD1 has a margin of $3.37^{\circ}$, while the swirl angle margin for AVD 2 is the largest, which is at $4.87^{\circ}$. 


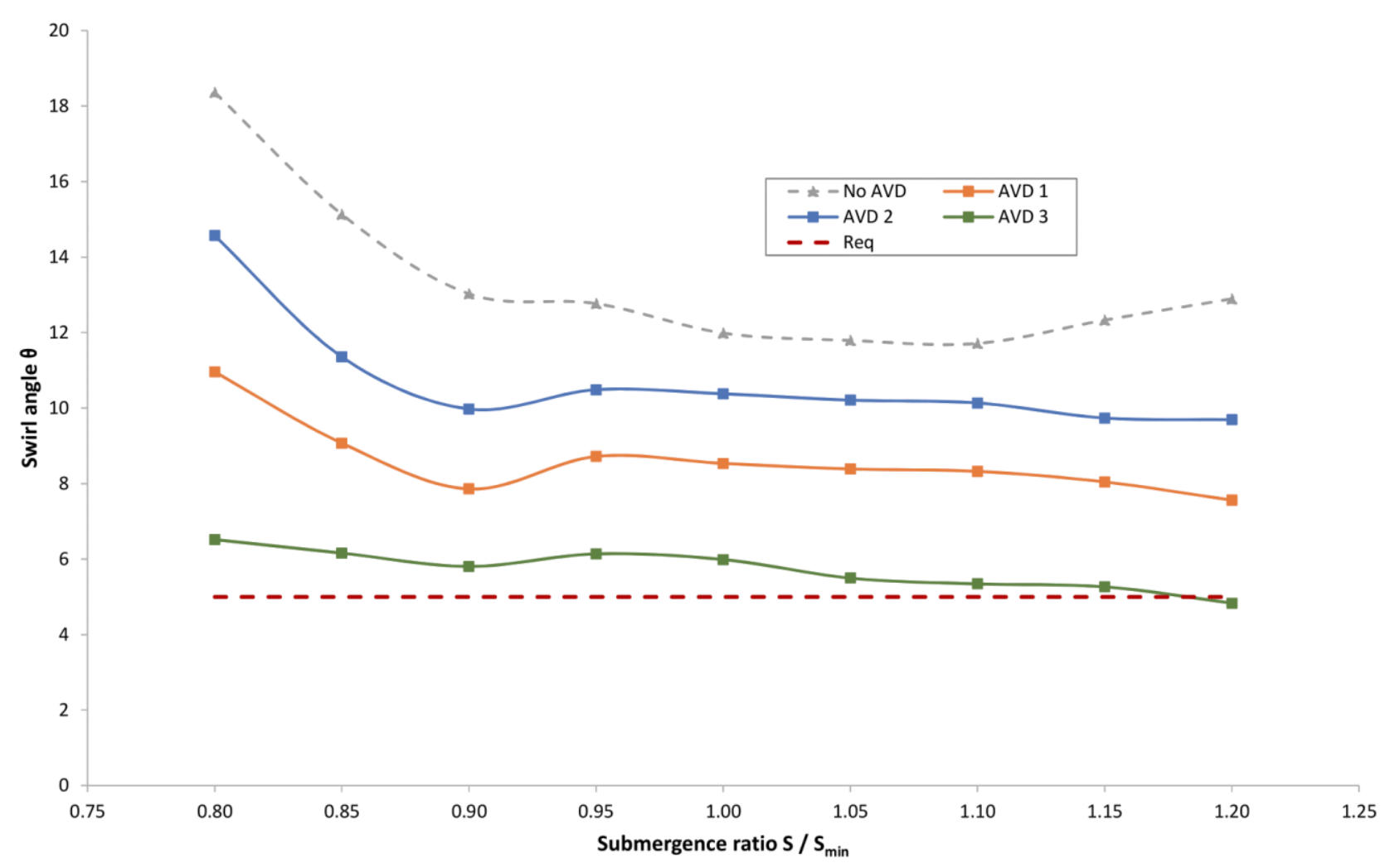

Fig. 4. Swirl angle values with different floor splitter heights

The trend of swirl angle values in Figure 5 indicates a different feature compared to the trend in Figure 4. For different floor splitter lengths, the swirl reduction effect is not apparent as it is in the case of height variation of floor splitter. The shorter floor splitter, which is AVD4, seems to be less effective than the base AVD, namely AVD1, which indicates that an exposure to a longer floor splitter is needed to improve the swirl reduction. As the length of the floor splitter increases, the trend of the swirl angle values shows only a slight reduction. This can be observed by the difference in the results for AVD1 and AVD5 which base length are $L$ and $L+D$ respectively. This implies that longer floor splitters do not improve the swirl reduction effect significantly. However, the margin of swirl angle values is much smaller for submergence ratio greater than 0.9 when installed with AVD5 which indicates a more stable swirl angle fluctuations compared to AVD1. The plot also shows that for submergence ratio greater than 1.1, the swirl angle values are not reduced further with the installation of AVD4 and AVD5, unlike the case with different floor splitter heights. The lowest swirl angle values for AVD4 and AVD5 do not lies at the maximum submergence ratio, but rather at the values between 0.9 and 1.1. Margins of swirl angle values do not differ much between AVD1, AVD4 and AVD5. The flow with AVD4 produces a margin above the requirement $\left(5.0^{\circ}\right)$ of $3.52^{\circ}$ and while flow with AVD5 produces $2.57^{\circ}$.

The lowest swirl angle values for AVD4 and AVD5 do not lies at the maximum submergence ratio, but rather at the values between 0.9 and 1.1. Margins of swirl angle values do not differ much between AVD1, AVD4 and AVD5. The flow with AVD4 produces a margin above the requirement $\left(5.0^{\circ}\right)$ of $3.52^{\circ}$ and while flow with AVD5 produces $2.57^{\circ}$. 


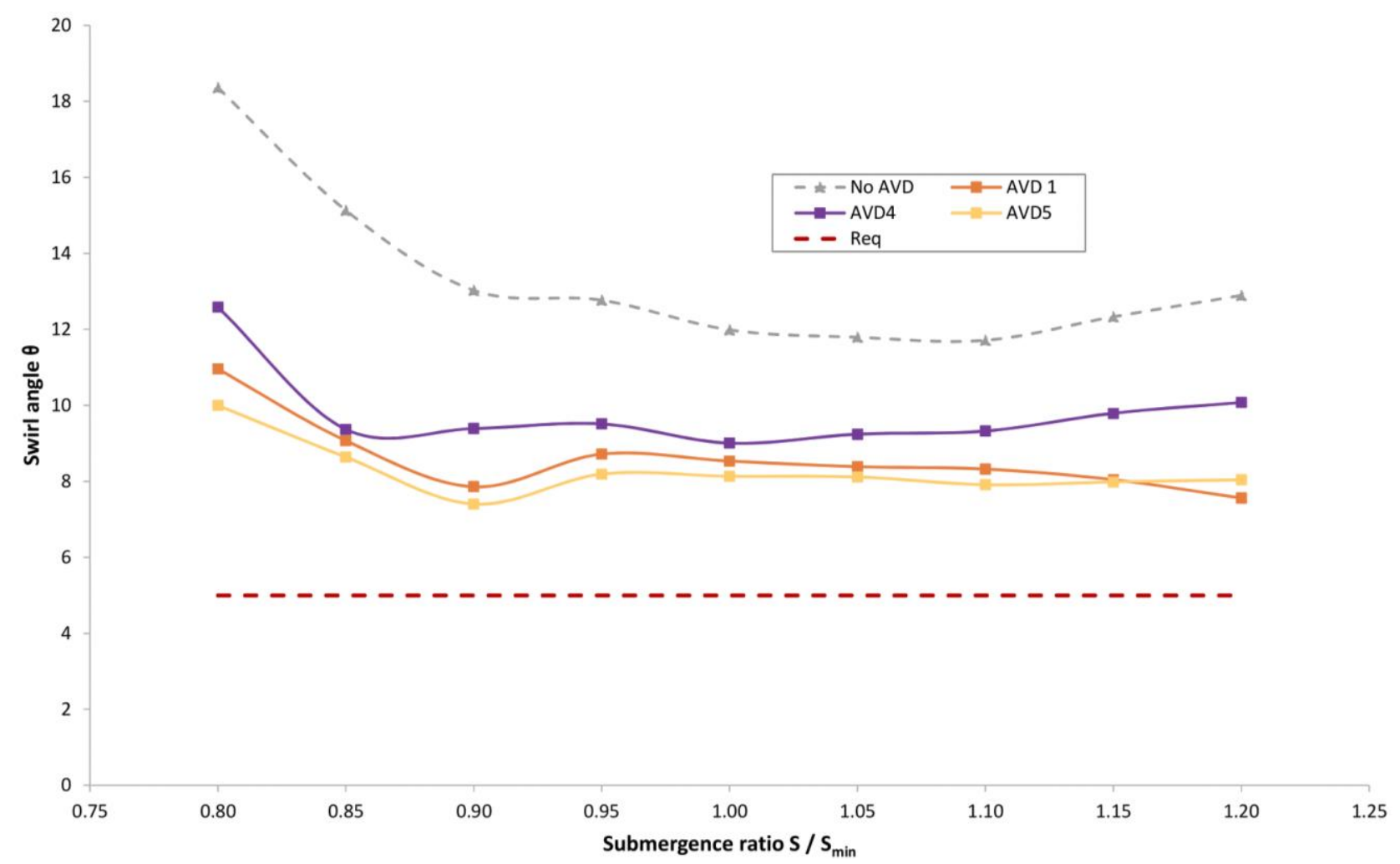

Fig. 5. Swirl angle values with different floor splitter lengths. Dashed horizontal line the minimum requirement $5.0^{\circ}$

\section{Conclusions}

The effect of floor splitter installation on the vortex formation near the suction inlet of a pump in pump sump has been studied in this research. A single intake pump sump model has been constructed to measure the swirl angle in the pump intake flow with and without floor splitter installed according to ANSI HI 9.82012 standard. Five plate type floor splitter variants were designed and tested in the pump sump model and the results have been compared. A floor with an inclination angle of $30^{\circ}$ is placed in the model to induce vortex formation at the suction inlet. The results show that the installation of floor splitter has successfully eliminated the vortex formed at the sump floor, however the swirl angle in the intake flow has not been reduced to the allowable value which is below $5^{\circ}$ based on the requirement in ANSI HI 9.82012 standard for most of the floor splitter variants. Floor splitters with varying heights display significant change in swirl reduction effect with higher floor splitters produce lower swirl angle values. The margin of swirl angle values has also been smaller in higher floor splitters which indicate a more stable fluctuation of swirl angles. The swirl reduction effect for varying floor splitter lengths does not change much compared to varying floor splitter heights. Longer floor splitters, however, produce an almost constant swirl angle values for submergence ratio greater than 0.9 . The advantages of each floor splitter dimension obtained from the results may be combined to get the best floor splitter shape.

\section{Acknowledgement}

The research has been funded by Ministry of Science, Technology, Environment and Climate Change (MESTECC), Malaysia under Science Fund grant No. SF1326 and carried out in collaboration with the Department of Irrigation and Drainage (DID), Malaysia. This research is also sponsored by research university grant GUP-2018-102. 


\section{References}

[1] Tsou, John L., B. W. Melville, R. Ettema, and T. Nakato. Review of flow problems at water intake pump sumps. No. CONF-941007-. American Society of Mechanical Engineers, New York, NY (United States), 1994.

[2] Norizan, Tajul A., Eslam Reda, and Zambri Harun. "Enhancement of vorticity reduction by floor splitter in pump sump to improve pump efficiency." Sustainable Energy Technologies and Assessments 26 (2018): 28-36. https://doi.org/10.1016/j.seta.2017.06.001

[3] Hydraulic Institute. American National Standard for Rotodynamic Pumps for Pump Intake Design. American National Standards Institute, Inc, 2012.

[4] The National Standards Authority of Ireland (NSAI). Rotodynamic Pumps - Design of Pump Intakes Recommendations for Installation of Pumps. Comite Europeen de Normalisation, Brussels, 2009.

[5] TSJ S002: Standard Method for Model Testing the Performance of a Pump Sump, Turbomachinery Society of Japan, Tokyo, 2005.

[6] Tullis, James Paul. "Modeling in design of pumping pits." Journal of the Hydraulics Division 105, no. 9 (1979): 10531063.

[7] Pradeep, S., G. Sayantan, P. G. Prasad, and M. S. Mohan Kumar. "CFD simulation and experimental validation of a horizontal pump intake system." ISH Journal of Hydraulic Engineering 18, no. 3 (2012): 173-185. https://doi.org/10.1080/09715010.2012.721183

[8] Chen, Hong-xun, and Jia-hong Guo. "Numerical simulation of 3-D turbulent flow in the multi-intakes sump of the pump station." Journal of Hydrodynamics 19, no. 1 (2007): 42-47.

https://doi.org/10.1016/S1001-6058(07)60026-2

[9] Matsui, Jun, Yuki Sugino, and Kenji Kawakita. "Numerical simulation on flow in pump sump with free surface." In Proceedings of $6^{\text {th }}$ International Symposium on Fluid Machinery and Fluids Engineering, pp 1-5. 2014. https://doi.org/10.1049/cp.2014.1249

[10] Taştan, Kerem, and Nevzat Yıldırım. "Effects of intake geometry on the occurrence of a free-surface vortex." Journal of Hydraulic Engineering 144, no. 4 (2018): 04018009. https://doi.org/10.1061/(ASCE)HY.1943-7900.0001439

[11] Guo, Z.W., Chen, F., Wu, P.F. and Qian, Z.D. "Three-dimensional simulation of air entrainment in a pump sump." Journal of Civil Engineering 23 (2017): 314-324.

[12] Isa, N. Mat, A. F. Ab Rahmanb, and A. Sadikinc. "Numerical Simulation of Splitting Devices in Horizontal Pipeline." Journal of Advanced Research in Applied Mechanics 5, no. 1 (2015): 8-14.

[13] Park, Inhwan, Hyung-Jun Kim, Hoje Seong, and Dong Sop Rhee. "Experimental studies on surface vortex mitigation using the floating anti-vortex device in sump pumps." Water 10, no. 4 (2018): 441. https://doi.org/10.3390/w10040441

[14] Lotfy, Eslam Reda, and Zambri Harun. "Effect of atmospheric boundary layer stability on the inclination angle of turbulence coherent structures." Environmental Fluid Mechanics 18, no. 3 (2018): 637-659. https://doi.org/10.1007/s10652-017-9558-4

[15] Kang, Won Tae, Byeong Rog Shin, and Doeg Hee Doh. "An effective shape of floor splitter for reducing sub-surface vortices in pump sump." Journal of Mechanical Science and Technology 28, no. 1 (2014): 175-182. https://doi.org/10.1007/s12206-013-1103-x

[16] Kim, Hyung-Jun, Sung Won Park, and Dong Sop Rhee. "Numerical analysis of the effects of anti-vortex device height on hydraulic performance of pump sump." KSCE Journal of Civil Engineering 21, no. 4 (2017): 1484-1492.

https://doi.org/10.1007/s12205-016-0714-z

[17] Batcha, Muhammad Azhar Akbar, Tajul Ariffin Norizan, Zulkhairi Zainol Abidin, Zambri Harun, and Wan Hanna Melini Wan Mohtar. "Vortex Measurement at Bell-Shaped Pump Inlet Using Particle Image Velocimetry." Jurnal Kejuruteraan 30, no. 2 (2018): 209-217.

https://doi.org/10.17576/ikukm-2018-30(2)-11

[18] Norizan, Tajul Ariffin, Zambri Harun, Shahrir Abdullah, and Wan Hanna Melini Wan Mohtar. "Effects of Floor Splitter Height on the Effectiveness of Swirl Angle Reduction in Pump Intake." Journal of Advanced Research in Fluid Mechanics and Thermal Sciences 57, no. 1 (2019): 32-39.

[19] Norizan, Tajul Ariffin, Zambri Harun, Wan Hanna Melini Wan Mohtar, and Shahrir Abdullah. "Characteristics of Swirl Angle in Pump Intake Flow Near the Minimum Inlet Submergence." In Proceedings of $8^{\text {th }}$ Joint Fluids Engineering Conference (AJKFluids2019), 2019.

https://doi.org/10.1115/AJKFluids2019-5053 